\title{
Response to the letter by Meng-jun Zhan et al. regarding the paper " $A$ technical report from the Italian SARS-CoV-2 outbreak. Postmortem sampling and autopsy investigation in cases of suspected or probable COVID-19"
}

\author{
Alessandro Santurro ${ }^{1}$ Matteo Scopetti ${ }^{1} \cdot$ Stefano $^{\prime}$ Errico $^{2} \cdot$ Vittorio Fineschi ${ }^{1}$ (I)
}

Accepted: 5 October 2020 / Published online: 26 October 2020

(c) Springer Science+Business Media, LLC, part of Springer Nature 2020

We have carefully read the letter sent by Zhan et al. [1], regarding our paper [2].

First of all, we thank you for recognizing the importance and practical usefulness of our paper.

In reference to the sentence that has been highlighted and which you have asked us to change, we believe that this request is the result of an incomplete understanding, perhaps dictated by an incorrect understanding of the English language, which has led the authors to write this letter.

Our sentence, in fact, is: "SARS-CoV-2 (severe acute respiratory syndrome-coronavirus-2) is a coronavirus responsible for COVID-19 (coronavirus disease 2019) which resulted in a cluster of cases of pneumonia that originated in China around 31 December 2019 and has subsequently spread across the globe" [2].

Although the authors have stated that we "claim that COVID-19 originated in China" the paper actually states that "a cluster of cases of pneumonia originated in China around 31 December 2019", a fact which is not in dispute. We also do not mention Wuhan. Our paper also states that coronavirus is responsible for COVID-19, another fact that is not in dispute [3-5].

We believe that when an author sends a letter to the Editor, it is first necessary for that author to fully understand the meaning of what they have read, otherwise we might believe that it is just a way for them to try to publish their own modest and unscientific point of view [6].

Vittorio Fineschi

vfinesc@tin.it

1 Department of Anatomical, Histological, Forensic and Orthopaedic Sciences, Sapienza University of Rome, Viale Regina Elena 336, 00185 Rome, Italy

2 Department of Medicine, Surgery and Health, University of Trieste, Strada di Fiume 44, 34149 Trieste, Italy

\section{References}

1. Zhan M-J, Huang Y, Deng Z-H. Regarding "A technical report from the Italian SARS-CoV-2 outbreak. Postmortem sampling and autopsy investigation in cases of suspected or probable COVID19”. Forensic Sci Med Pathol. 2020. https://doi.org/10.1007/s1202 4-020-00322-4

2. Santurro A, Scopetti M, D’Errico S, Fineschi V. A technical report from the Italian SARS-CoV-2 outbreak. Postmortem sampling and autopsy investigation in cases of suspected or probable COVID19. Forensic Sci Med Pathol. 2020;16:471-6.

3. Bogdanović M, Atanasijević T, Popović V, et al. Is the role of forensic medicine in the covid-19 pandemic underestimated? Forensic Sci Med Pathol. 2020. https://doi.org/10.1007/s1202 4-020-00308-2.

4. Khoo LS, Hasmi AH, Ibrahim MA, et al. Management of the dead during COVID-19 outbreak in Malaysia. Forensic Sci Med Pathol. 2020;16:463-70.

5. Fineschi V, Aprile A, Aquila I, et al. Management of the corpse with suspect, probable or confirmed COVID-19 respiratory infection - Italian interim recommendations for personnel potentially exposed to material from corpses, including body fluids, in morgue structures and during autopsy practice. Pathologica. 2020;112:64-77.

6. Byard RW, Tsokos M. Research, publishing, and forensic pathology. Forensic Sci Med Pathol. 2005;1:237-8.

Publisher's note Springer Nature remains neutral with regard to jurisdictional claims in published maps and institutional affiliations. 